\title{
Intradermal Delivery of Antisense Oligonucleotides by the Pulse Depolarization Iontophoretic System
}

\author{
Yukihiko AramaKi, Hidetoshi Arima, ${ }^{1)}$ Mamiko TaKahashi, Eriko MiYAZAKI, Takatoshi SAKAmoto, \\ and Seishi TsuchIY** \\ School of Pharmacy, Tokyo University of Pharmacy and Life Science; 1432-1 Horinouchi, Hachioji, Tokyo 192-0392, \\ Japan. Received April 17, 2003; accepted June 12, 2003
}

\begin{abstract}
The intradermal delivery of an antisense oligonucleotide was examined by iontophoresis. In this experiment, the antisense sequence of $\left[{ }^{32} \mathrm{P}\right]$-labeled phosphodiester oligonucleotide $\left(\left[{ }^{32} \mathrm{P}\right] \mathrm{D}\right.$-oligo, 18-mer) hybridizing to mouse interleukin 10 (IL-10) mRNA was used as a model D-oligo. In in vitro iontophoretic experiments, isolated hairless mouse skin was used with a horizontal diffusion cell. The enhancing effect of pulse depolarization (PDP) iontophoresis on the $\left[^{32} \mathrm{P}\right] \mathrm{D}$-oligo permeation through the skin was better, and the skin irritation was less, than those of constant direct current $(\mathrm{CDC})$ iontophoresis. The apparent fluxes of $\left[{ }^{32} \mathrm{P}\right] \mathrm{D}$-oligo were enhanced with the increasing current densities and $\left[{ }^{32} \mathrm{P}\right] \mathrm{D}$-oligo concentrations in the donor solution, whereas the enhanced flux decreased with the increasing $\mathrm{NaCl}$ concentrations in the donor solution. An optimum electric current was observed for the intradermal delivery of $\left[{ }^{32} \mathrm{P}\right] \mathrm{D}$-oligo, and intact $\left[{ }^{32} \mathrm{P}\right] \mathrm{D}$-oligo was detected within the skin after iontophoresis for $6 \mathrm{~h}$. These results suggest that PDP iontophoresis may be useful for the intradermal delivery of antisense oligonucleotides.
\end{abstract}

Key words antisense oligonucleotide; iontophoresis; intradermal delivery; hairless mouse skin

Antisense oligonucleotides designed to hybridize specifically to heterogeneous nuclear RNA or mature mRNA sequences have been shown to inhibit the expression of numerous genes both in vitro and in vivo.,3) They have been considered as a promising candidate for nucleic acid drugs to realize gene-specific therapeutics for the treatment of malignant, viral, inflammatory, and autoimmune diseases. ${ }^{2,3)}$

$\mathrm{CD}^{+}$helper $\mathrm{T}(\mathrm{Th})$ cells have been subdivided into at least two subsets, Th1 and Th2, on the basis of their cytokine secretion. ${ }^{4,5}$ The balance of Th1 and Th2 cells is relevant to the outcome of immunologically mediated clinical syndromes, suggesting that $\mathrm{Th} 2$ is predominant in atopic dermatitis (AD). ${ }^{6}$ Interleukin-10 (IL-10) is initially characterized as a counter-regulatory cytokine for Th1 development, ${ }^{4)}$ and the overexpression of IL-10 in AD may contribute to the down-regulation of Th1 response. ${ }^{7,8)}$ Therefore, the regulation of IL-10 production may provide a potentiality for the immunotherapeutic intervention of $\mathrm{AD}$. We reported that 18-mer antisense phosphorothioate oligonucleotide (S-oligo) hybridizing to the sequence of the $3^{\prime}$-untranslated region of mouse IL-10 mRNA inhibits the IL-10 production in macrophages. ${ }^{9)}$ IL-10 antisense oligonucleotides may have a potentiality for $\mathrm{AD}$ treatment, provided that the antisense oligonucleotide can be delivered to the IL-10 producing cells such as macrophages, ${ }^{7,10)}$ dendritic cells, ${ }^{10)}$ Langerhans' cells, ${ }^{11)}$ keratinocytes, ${ }^{11)}$ and $\mathrm{T}$ cells ${ }^{12)}$ in the skin.

In general, oligonucleotides are membrane-impermeable due to their high ionization, low-lipophilicity and high molecular weight. There are some reports on the improvement of transdermal delivery of antisense oligonucleotides across the stratum corneum with absorption enhancers ${ }^{13}$ ) or by iontophoresis $^{14-17)}$ and electroporation. ${ }^{18,19)}$ Iontophoresis is classified by the current flow pattern into constant direct current (CDC), pulse direct current (PDC), and pulse depolarization current (PDP). CDC iontophoresis is the most common, but its use is sometimes restricted by irritation attributed to the skin polarization. PDP iontophoresis provides a high frequency electric pulse and opens a depolarization cir- cuit between pulses, so that the skin irritation is subsequently less in spite of the relatively high current density. ${ }^{20)}$ However, there is no paper on the iontophoretic delivery of antisense oligonucleotides using PDP iontophoresis.

In the present study, we examined the permeation of phosphodiester oligonucleotide (D-oligo) having the antisense sequence to mouse IL-10 mRNA through isolated hairless mouse skin using PDP iontophoresis in vitro. To acquire basic information on the skin permeation of antisense oligonucleotides, D-oligo was used. In this paper, the advantages of PDP iontophoresis, permeation characteristics and the distribution and stability of D-oligo are discussed. It was observed that $\mathrm{D}$-oligo could be delivered into the shallow layer of the skin effectively by PDP iontophoresis.

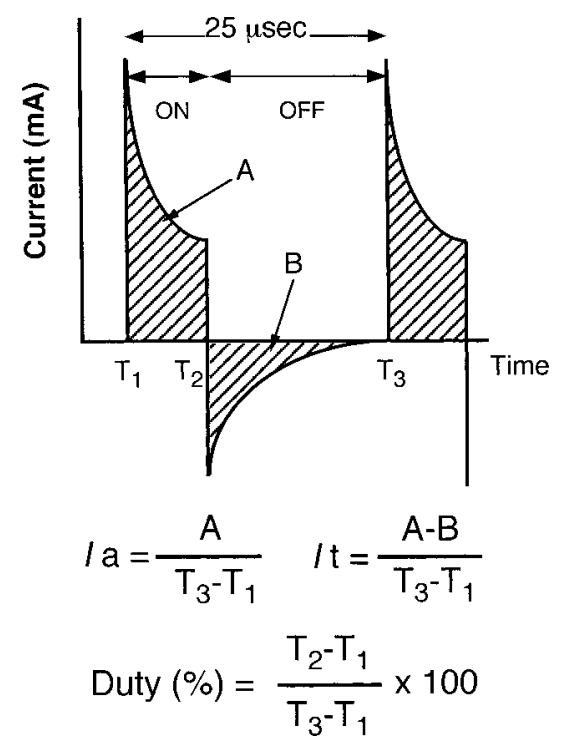

Fig. 1. Electric Current Pattern of PDP Iontophoresis System $I_{\mathrm{a}}$ : current applied to the skin, $I_{\mathrm{t}}$ : current transported through the skin. 


\section{MATERIALS AND METHODS}

Chemicals and Reagents $\gamma-\left[{ }^{32} \mathrm{P}\right]$ ATP was obtained from Daiichi Pure Chemicals (Tokyo, Japan). Proteinase K was purchased from Nippon Gene (Toyama, Japan). All other chemicals and solvents were of the analytical reagent grade.

Oligonucleotides D-oligos purified by high performance liquid chromatography were purchased from Amersham Pharmacia Biotech (Tokyo). The sequences of D-oligos used here are as follows: 5'-AGGTCCTGGAGTCCAGCA-3' (antisense sequence corresponding to 637-654 of mouse IL-10 mRNA, 18-mer), 5'-AGGTCCTGG-3' (9-mer), 5'-AGGTCCTGGAGT-3' (12-mer), 5'-AGGTCCTGGAGTCCA-3' (15mer) and 5' -AGGTCCTGGAGTCCAGCAGAC-3' (21-mer).

Radiolabeling D-oligo was labeled using a $5^{\prime}$-endlabeling kit (MEGALABEL, Takara, Tokyo) with T4 polynucleotide kinase and $\left.\gamma-{ }^{32} \mathrm{P}\right] \mathrm{ATP}$ according to the manufacturer's protocol. $\left[{ }^{32} \mathrm{P}\right]$ Labeled D-oligo $\left(\left[{ }^{32} \mathrm{P}\right] \mathrm{D}\right.$-oligo $)$ was purified using Microcon-3 (Amicon, Tokyo) and then a QIAquick Nucleotide Removal Kit (Qiagen, Tokyo). Radiochemical purity $(>c a .99 \%)$ was checked by polyacrylamide electrophoresis. The average specific activity was $c a$. 3.6 $\mathrm{Ci} / \mathrm{nmol}$.

Iontophoretic Experiment Abdominal skin of female hairless mice (6-8 weeks old, SLC Inc., Shizuoka, Japan) was isolated, and the adhered fat and visceral tissues were removed. The skin of a $2.5 \mathrm{~cm}^{2}$ area was placed between the donor and receptor compartments of a horizontal diffusion cell system. The cathodal (donor) chamber contained $1.0 \mathrm{ml}$ of donor solution (100 $\mu \mathrm{M}$ of Tris-HCl buffer, $\mathrm{pH} 7.5)$, and the anodal (receptor) chamber was filled with $3.7 \mathrm{ml}$ of $0.45 \%(\mathrm{w} / \mathrm{v}) \mathrm{NaCl}$ solution. As D-oligos are negatively charged at neutral $\mathrm{pH}, 1 \mu \mathrm{Ci}\left[{ }^{32} \mathrm{P}\right] \mathrm{D}$-oligo $(0.5 \mu \mathrm{g})$ was added to the cathodal chamber. $\mathrm{Ag} / \mathrm{AgCl}$ (anodal and cathodal) electrodes were then connected to a Hisamitsu ADIS4030 power supply apparatus (Hisamitsu Pharmaceutical Co., Tokyo). The approved pattern of PDP current is shown in Fig. 1. Experiments were performed at $40 \mathrm{kHz}$ with a $30 \%$ duty and a constant current of $0.3 \mathrm{~mA}$ (current transported through the skin, $I_{\mathrm{t}}$ ) at $25^{\circ} \mathrm{C}$, unless specifically described. At given times, an aliquot of $100 \mu \mathrm{l}$ of sample solution was withdrawn from the receptor or donor compartment and replaced by an equal volume of fresh solution. In the case of $\left[{ }^{32} \mathrm{P}\right] \mathrm{D}$-oligo distribution in the skin, the whole skin, after $6 \mathrm{~h}$ of iontophoresis, was dissolved in $3 \mathrm{ml}$ of tissue lysis solution (Soluene-350, Packard, Tokyo). An aliquot of sample solution and/or the skin lysate were added to $5 \mathrm{ml}$ of scintillation cocktail (Hionic-Fluor, Packard, Tokyo), and the radioactivities were measured by an Aloka-3000 liquid scintillation counter (Aloka, Tokyo). All data were given as means \pm S.E.M.

Extraction and Electrophoresis of D-Oligo The whole skin after PDP iontophoresis was added to $1 \mathrm{ml}$ of DNA extraction buffer $(0.5 \%$ SDS, $10 \mathrm{~mm} \mathrm{NaCl}, 20 \mathrm{~mm}$ Tris-HCl, $10 \mathrm{~mm}$ EDTA, pH 7.6) and was homogenized with a Polytron homogenizer (Kinematica AG, Tokyo). Proteinase K solution (final concentration $1 \mathrm{mg} / \mathrm{ml}$ ) was added to the homogenate and incubation followed for $2 \mathrm{~h}$ at $55^{\circ} \mathrm{C}$. After addition of $500 \mu \mathrm{l}$ of phenol/chloroform $(1: 1 \mathrm{v} / \mathrm{v})$ solution to the homogenate, the mixture was centrifuged to extract $\left[{ }^{32} \mathrm{P}\right] \mathrm{D}$ oligo into the upper aqueous layer. Aliquots of the donor and receptor solutions and the skin-extracted solution were electrophoresed for $60 \mathrm{~min}$ at $200 \mathrm{~V}$ on $20 \%$ polyacrylamide gel. The gel was dried and the radioactivities were estimated by a BAS-2000 (Fujifilm, Tokyo).

\section{RESULTS}

Evaluation of PDP Iontophoresis In in vitro PDP iontophoresis of $\left.{ }^{32} \mathrm{P}\right] \mathrm{D}$-oligo using a diffusion cell attached with hairless mouse skin, the apparent permeation of D-oligo was estimated by periodically measuring the radioactivity in the receptor solution. CDC iontophoresis is the most common, so the permeation of D-oligos was compared to that of PDP iontophoresis. Without loading of electric current, no radioactivity was observed in the receptor compartment, but significantly high radioactivities were detected by both types of electric current, CDC and PDP (Fig. 2). PDP iontophoresis was more effective for $\left.{ }^{32} \mathrm{P}\right] \mathrm{D}$-oligo permeation than was CDC iontophoresis.

The skin injury by iontophoresis was preliminarily evaluated by measuring the release of protein from the skin into the receptor solution. As shown in Fig. 3, the absorbance at $280 \mathrm{~nm}$ increased by iontophoresis time-dependently, and was higher by CDC than by PDP iontophoresis at each point. Figure 4 shows the permeation profiles obtained from the

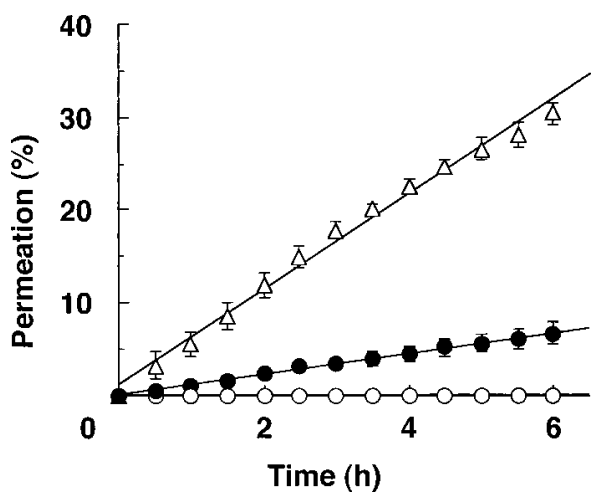

Fig. 2. Increased Permeation of $\left[{ }^{32} \mathrm{P}\right] \mathrm{D}-\mathrm{Oligo}$ by Iontophoresis

$\bigcirc$ : current off, $\triangle$ : PDP iontophoresis, $\bigcirc$ : CDC iontophoresis. Permeation (\%) was estimated from the penetrated radioactivity during CDC or PDP iontophoresis. The current density and the chain length of $\left[{ }^{32} \mathrm{P}\right] \mathrm{D}$-oligo were $0.3 \mathrm{~mA}$ and $18-\mathrm{mer}$, respectively. Each point represents the mean \pm S.E.M. from $4-6$ experiments.

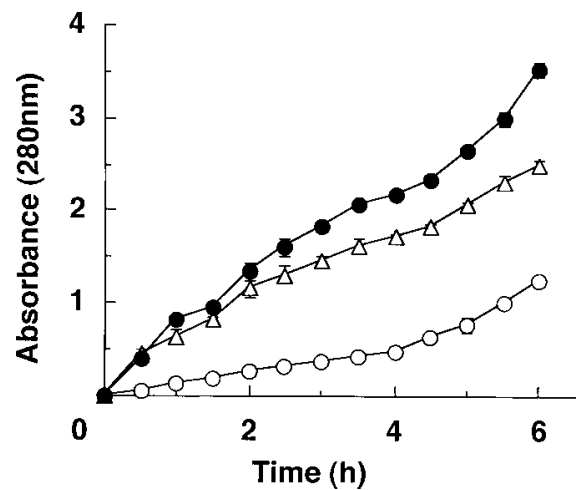

Fig. 3. Concentration of Protein in the Receptor Compartment during Iontophoresis

O: current off, $\triangle$ : PDP iontophoresis, 0 : CDC iontophoresis. Released protein from the skin was monitored at $280 \mathrm{~nm}$. The current density was $0.3 \mathrm{~mA}$ without using $\left[{ }^{32} \mathrm{P}\right] \mathrm{D}$-oligo. Each point represents the mean \pm S.E.M. from $4-6$ experiments. 
continual (triangle) and intermittent (circle, square) electric current flows by PDP iontophoresis. Permeation of $\left[{ }^{32} \mathrm{P}\right] \mathrm{D}-$ oligo accelerated by iontophoresis (circle, $0-2 \mathrm{~h}$ ) was reduced by discontinuation of the current flow $(2-4 \mathrm{~h})$, and when the skin was reloaded by the current flow $(4-6 \mathrm{~h})$, permeation increased again and was restored to the initial level $(0-2 \mathrm{~h})$. The recovery of skin impermeability after termination of electric current (square, 5-6h) was also observed after iontophoresis for a longer period of $4 \mathrm{~h}$. These results suggest that PDP iontophoresis will give a prominent electric pattern for the transdermal delivery of D-oligo and will result in low levels of skin injury.

Iontophoretic Permeation Characteristics of D-Oligo The cumulative radioactivity in the receptor solution was estimated by the constant current, and the apparent flux was calculated from the slope of the regression line. Figure 5A shows the effects of current densities of PDP iontophoresis on the apparent flux of $\left[{ }^{32} \mathrm{P}\right] \mathrm{D}$-oligo. The fluxes of $\left[{ }^{32} \mathrm{P}\right] \mathrm{D}$ oligo increased proportionally with the increasing current density. A linear relationship is observed between the concentrations of $\left[{ }^{32} \mathrm{P}\right] \mathrm{D}$-oligo and the fluxes (Fig. 5B). Figure $5 \mathrm{C}$ shows the semi-logarithmic plot of the effects of ionic strength on the flux of $\left[{ }^{32} \mathrm{P}\right] \mathrm{D}$-oligo. By increasing $\mathrm{NaCl}$ concentrations in the donor solution, the $\left[{ }^{32} \mathrm{P}\right] \mathrm{D}$-oligo flux was

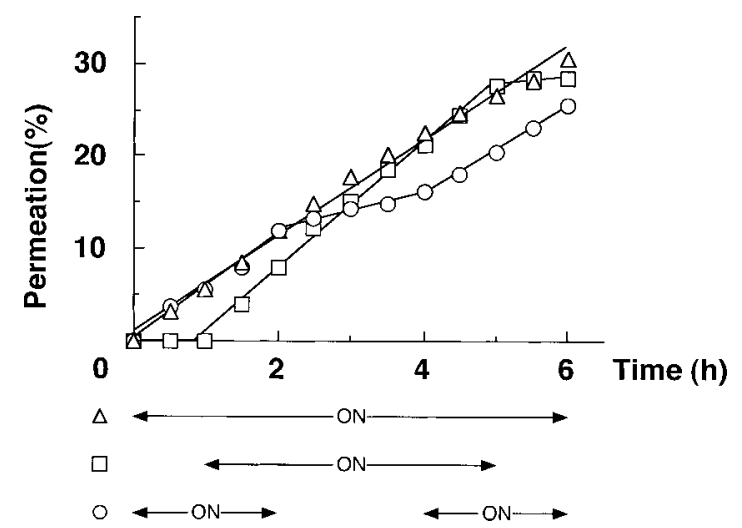

Fig. 4. Permeation of $\left[{ }^{32} \mathrm{P}\right] \mathrm{D}$-Oligo by the Continuous and Intermittent Electric Current of PDP Iontophoresis

The periods of current applied are shown under the abscissa by arrows. Permeation (\%) was estimated from the penetrated radioactivity. The current density and the chain length of $\left[{ }^{32} \mathrm{P}\right] \mathrm{D}$-oligo were $0.3 \mathrm{~mA}$ and 18 -mer, respectively. Each point represents the mean \pm S.E.M. from 3 experiments. decreased and obeyed the first-order equation, as a result of competition with $\mathrm{Cl}^{-}$.

The fluxes were estimated using different chain lengths of $\left[{ }^{32} \mathrm{P}\right] \mathrm{D}$-oligos $(9-21 \mathrm{mer})$. Contrary to our expectations, the apparent flux increased with increasing chain length (Fig. 6). The permeations of 4 kinds of homooligomers of $\left[{ }^{32} \mathrm{P}\right] \mathrm{D}-$ oligo (18 mer) are shown in Fig. 7. Poly A showed a significant value and poly $\mathrm{T}$ showed the same permeation as the antisense sequence of $\left[{ }^{32} \mathrm{P}\right] \mathrm{D}$-oligo $(18 \mathrm{mer})$, but the permeations of poly $\mathrm{C}$ and poly $\mathrm{G}$ were smaller.

Distribution and Stability of D-Oligo in the Skin Following $6 \mathrm{~h}$ PDP iontophoresis of $\left[{ }^{32} \mathrm{P}\right] \mathrm{D}$-oligo at various current densities, the radioactivities in the donor, skin and receptor compartments were measured. As current density increased, the radioactivities in the receptor compartment increased and those in the donor compartment were decreased (Fig. 8). The radioactivities in the skin showed the maximum value at $0.3 \mathrm{~mA}$ ( $c a .37 \%$ of total radioactivity). The average recovery of radioactivity was $99.5 \%$, suggesting that adsorption of radioactivity onto the diffusion cell was negligible.

The stability of $\left[{ }^{32} \mathrm{P}\right] \mathrm{D}$-oligo during and after PDP iontophoresis was evaluated by polyacrylamide gel electrophoresis. Sample solutions withdrawn from the donor and receptor compartments periodically and the skin-extracted

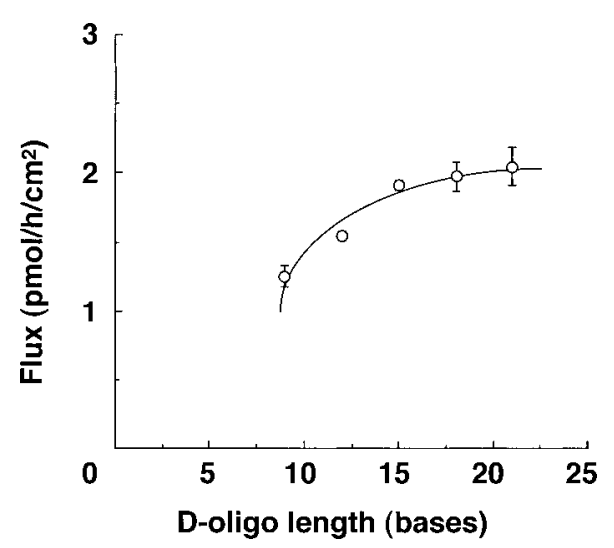

Fig. 6. The Effects of Chain Lengths on the Flux of $\left[{ }^{32} \mathrm{P}\right] \mathrm{D}-\mathrm{Oligo}$

The lengths of $\left[{ }^{32} \mathrm{P}\right] \mathrm{D}$-oligo are shown on the abscissa and the sequences are described in the Experimental. The flux was calculated from the slope of the linear regression line of the permeation experiment. The current density was $0.3 \mathrm{~mA}$. Each value represents the mean \pm S.E.M. from $3-4$ experiments.
A

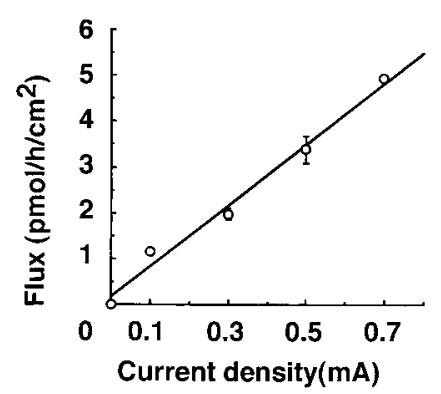

B

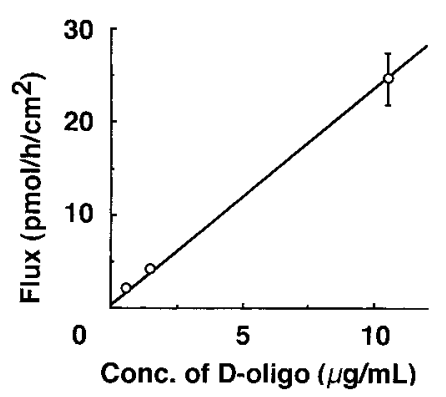

\section{C}

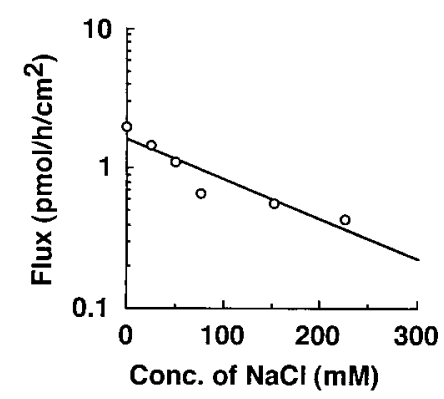

Fig. 5. Permeation Characteristics of $\left[{ }^{32} \mathrm{P}\right] \mathrm{D}-$ Oligo by PDP Iontophoresis

(A) Effects of current density: The current densities are shown on the abscissa. (B) Effects of [ $\left.{ }^{32} \mathrm{P}\right] \mathrm{D}$-oligo concentration $(0.6,1.5,10.5 \mu \mathrm{g} / \mathrm{ml})$ in the donor compartment: The current density was $0.3 \mathrm{~mA}$. (C) Effects of $\mathrm{NaCl}$ concentration added to the donor compartment: The current density was $0.3 \mathrm{~mA}$. The flux is calculated from the slope of the linear regression line of the permeation experiment. The chain length of $\left[{ }^{32} \mathrm{P}\right] \mathrm{D}$-oligo was 18 -mer. Each point represents the mean \pm S.E.M. from 3 experiments. 


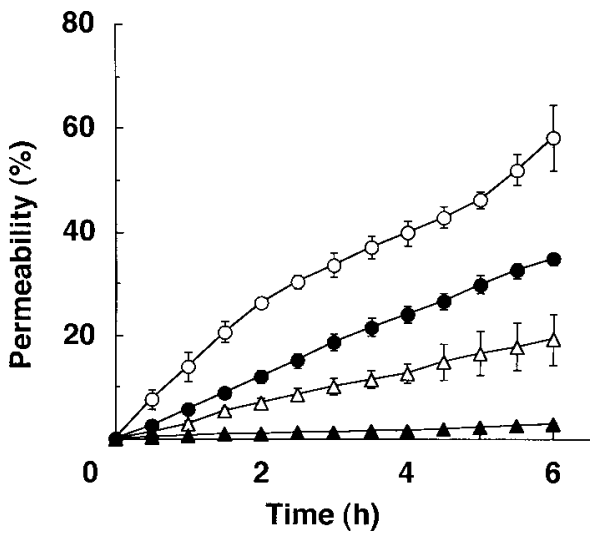

Fig. 7. Permeation of $\left[{ }^{32} \mathrm{P}\right]$ Homooligomers by PDP Iontophoresis

O: poly A, $\bullet$ : poly T, $\triangle$ : poly C, $\mathbf{\Lambda}$ : poly G. Permeation (\%) was estimated from the penetrated radioactivity. The current density and the chain length were $0.3 \mathrm{~mA}$ and 18 mer, respectively. Each value represents the mean \pm S.E.M. of 3 experiments.

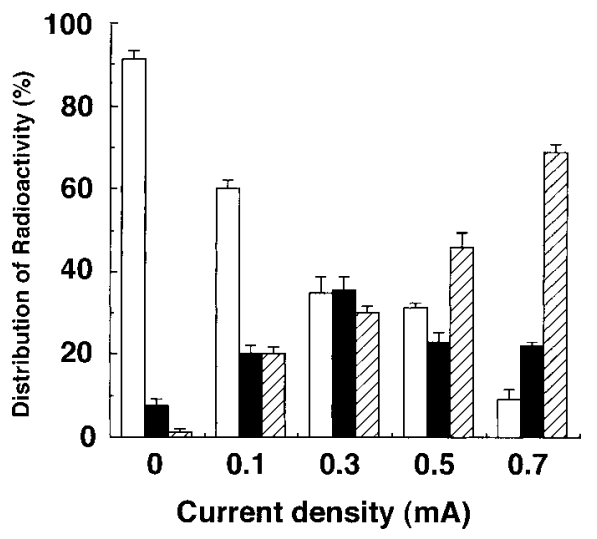

Fig. 8. The Effects of Current Density on the Distribution Pattern of Radioactivity after PDP Iontophoresis for $6 \mathrm{~h}$

The radioactivity in the donor $(\square)$, skin $(\square)$ and receptor $(\square)$ compartment. The current densities are shown on the abscissa. The chain length of $\left[{ }^{32} \mathrm{P}\right] \mathrm{D}$-oligo was 18 mer. The results are represented as mean $(\%) \pm$ S.E.M. from 3 experiments.
A

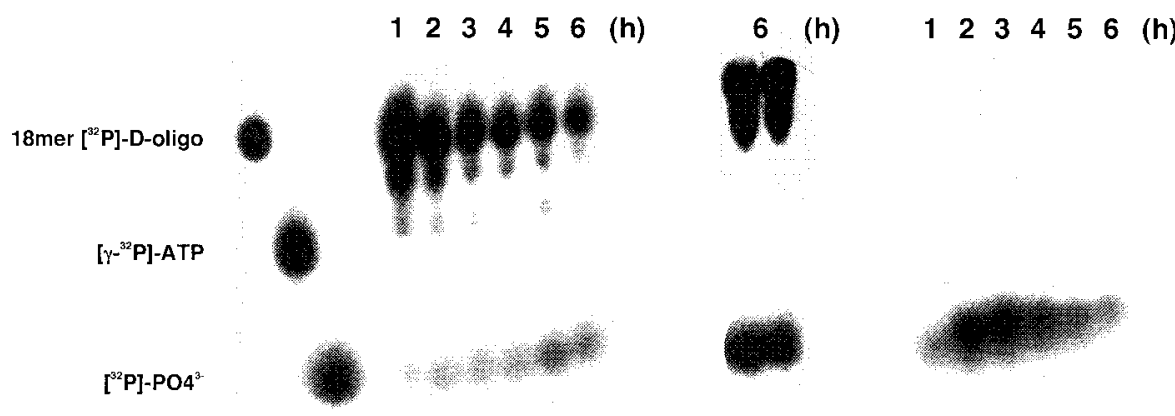

Fig. 9. Stability of $\left[{ }^{32} \mathrm{P}\right] \mathrm{D}-\mathrm{Oligo}$ during and after PDP Iontophoresis

(A) donor compartment $(1-6 \mathrm{~h})$, (B) skin $($ after $6 \mathrm{~h}),(\mathrm{C})$ : receptor compartment $(1-6 \mathrm{~h})$. The current density and the chain length of [ $\left.{ }^{32} \mathrm{P}\right] \mathrm{D}-\mathrm{oligo}$ were $0.3 \mathrm{~mA}$ and 18 -mer, respectively. The sample obtained from each compartment was subjected to polyacrylamide gel (20\%) electrophoresis. Each lane of (B) is the individual sample from two separate experiments.

solution after iontophoresis for $6 \mathrm{~h}$ were subjected to polyacrylamide gel electrophoresis, and their radioactivities were estimated. As shown in Fig. 9A, the radioactivities of intact $\left[{ }^{32} \mathrm{P}\right] \mathrm{D}$-oligo and its monomeric degrade, $\left[{ }^{32} \mathrm{P}\right] \mathrm{ATP}$, in the donor compartment decreased, and their complete degradation product, $\left[{ }^{32} \mathrm{P}_{\mathrm{O}} \mathrm{O}_{4}^{3-}\right.$, increased time-dependently. In the receptor compartment, no intact $\left[{ }^{32} \mathrm{P}\right] \mathrm{D}$-oligo was observed during or after iontophoresis (Fig. 9C). But in the skin (Fig. $9 \mathrm{~B})$, radioactivities originating in intact $\left[{ }^{32} \mathrm{P}\right] \mathrm{D}$-oligo were observed in the sample after PDP iontophoresis for $6 \mathrm{~h}$. The percentage of intact $\left[{ }^{32} \mathrm{P}\right] \mathrm{D}$-oligo was $67 \%$ of total radioactivity observed in the skin.

\section{DISCUSSION}

We know of few reports concerning antisense oligonucleotide by PDP iontophoresis. Hence, we assume that this is the first report showing the advantages of PDP iontophoresis in the intradermal delivery of antisense $\left[{ }^{32} \mathrm{P}\right] \mathrm{D}$-oligo.

PDP iontophoresis has desirable electrical characteristics having a depolarization process between high electric pulses (Fig. 1). The depolarization process restores the electrical po- larized state of the skin to its initial state and contributes to the elimination of skin irritation. ${ }^{20)}$ The slight increase in $\left[{ }^{32} \mathrm{P}\right] \mathrm{D}$-oligo permeation observed when the current flow was interrupted (Fig. 4, circle $2-4 \mathrm{~h}$ and square 5-6h) would be the reservoir effects of the skin as described by Scheuplein et al. ${ }^{21)}$

The Nernst-Planck equation, a trinomial equation, consisting of the passive flux, the electrophoretic movement, and the convective flow, describes the membrane transport of ions under an electric field and often has been used to describe iontophoretic transport. ${ }^{22)}$ In the present study, the passive flux is probably negligible because little permeation was observed without current or after the current broke off (Figs. 2, $4)$. The contribution of convective flow is also negligible because no $\left[{ }^{32} \mathrm{P}\right] \mathrm{D}$-oligo flux was observed from the anodal side (data not shown). Therefore, the enhanced permeation of $\left.{ }^{32} \mathrm{P}\right] \mathrm{D}$-oligo by PDP iontophoresis may well be attributable to the electrophoretic movement. This consideration may be supported by the fact that the apparent flux of $\left[{ }^{32} \mathrm{P}\right] \mathrm{D}$-oligo increased proportionally to the current density (Fig. 5A) and to its initial concentrations (Fig. 5B), but decreased with addition of $\mathrm{NaCl}$ to the donor solution (Fig. 5C). When co-ions, 
more electrically mobile than a drug of interest, are added to the donor solution, these ions move more easily across the skin competing with the drug. Therefore, an increase in the concentrations of chloride anion in the donor solution led to a decrease in the flux of polyanionic molecule, D-oligo, according to the first order kinetics (Fig. 5C). On the other hand, Oldenburg et al. ${ }^{15)}$ reported that the change in the $\mathrm{NaCl}$ concentrations from 50 to $200 \mathrm{~mm}$ had no appreciable effect on the transdermal flux of D-oligo. The difference between their results and ours can be attributed to the dissimilarity of experimental conditions, i.e., the current pattern, no use of inhibitors of degradative enzymes, the length and sequence of D-oligo, etc.

It is well known that the iontophoretic mobility of drugs is decreased with the increasing molecular weight due to their low diffusibility. However, Brand et $a l^{23)}$ reported that there was no relationship between antisense oligonucleotide chain length or base composition and the flux. In this study, we obtained unexpected results, i.e., the fluxes of $\left[{ }^{32} \mathrm{P}\right] \mathrm{D}$-oligos with longer chain lengths showed higher values than those with shorter ones (Fig. 6). No relationship could be observed between $\mathrm{C}: \mathrm{G}$ contents of $\left[{ }^{32} \mathrm{P}\right] \mathrm{D}$-oligos and the flux (data not shown). Furthermore, different homooligomers of the same length showed different permeation (Fig. 7). Brand et al. ${ }^{23)}$ reported that nucleotide in the antisense sequence significantly affects the iontophoretic permeation, e.g., the deoxyguanylic acid located at 3 '-terminal shows a higher flux. However, in our experiment, the flux of 9 -mer $\left[{ }^{32} \mathrm{P}\right] \mathrm{D}$-oligo having deoxyguanylic acid was lowest (Fig. 6). The relationships between the chain length or base composition of Doligo and the flux remain unclear. Other factors such as the high-order structure of D-oligo might contribute to iontophoretic transport.

Considering the delivery of antisense oligonucleotides, which control cytokine levels originating from dendritic cells, Langerhans' cells and keratinocytes, the amounts of intact D-oligo retained in the shallow layer of skin would be crucial for its effects. The antisense oligonucleotides, negatively regulating IL-10 production, will not necessarily enter the bloodstream, but are kept within the skin or directly enter the target cells, localizing in the epidermis. We anticipated that the amount of D-oligo retained in the skin would be directly proportional to that of D-oligo which penetrated the skin and/or permeated to the receptor compartment. However, the optimum value of $0.3 \mathrm{~mA}$ current density was observed in the skin-retained $\left[{ }^{32} \mathrm{P}\right] \mathrm{D}$-oligo (Fig. 8). An adequate current is believed necessary for retention of D-oligo within the dermis, and a stronger current may deliver D-oligo to the deeper layer. The optimum value would be variable among animals and experimental conditions.

The stability of D-oligo in the skin is also important. Oldenburg et al. ${ }^{15)}$ reported that D-oligo which penetrates into the skin is degraded by DNase and phosphatase, but there is no data on its stability in the skin. Our results indicate that ca. $37 \%$ of applied radioactivities was detected in the hairless mouse skin under the optimum conditions (Fig. 8) and two-thirds of those in the skin remained as intact $\left[{ }^{32} \mathrm{P}\right] \mathrm{D}$ oligo after PDP iontophoresis for $6 \mathrm{~h}$ (Fig. 9). In our experiments, no degradation of $\left[{ }^{32} \mathrm{P}\right] \mathrm{D}$-oligo was observed without skin after iontophoresis (data not shown). This suggests that D-oligo will be degraded in viable skin, because the stratum corneum lacks activities of DNase and phosphatase, and that the degradation products in the receptor solution would be derived from those in viable skin. These results suggest that PDP iontophoresis has significant potential for the topical delivery of D-oligo, rather than its systemic delivery into the bloodstream. As shown in Fig. 9C, D-oligo was easily decomposed during its penetration through the skin, thus its permeation following PDP iontophoresis did not reflect the penetration of intact D-oligo.

Regnier and Préat ${ }^{19)}$ reported that FITC-labeled S-oligos were detected in the nucleus of keratinocytes within a few minutes after electroporation, but not by CDC iontophoresis. We did not examine the uptake of D-oligos by the target cells in this study, but expected an effective cellular delivery of Doligo by PDP iontophoresis because it provides the skin with high frequency pulses like those in electroporation.

In many antisense studies, S-oligos are preferentially used because of their stability against DNase in the bloodstream, in spite of their complexities of many diastereomers and low hybridizing energy. This paper shows that PDP iontophoresis has significant advantages for the intradermal delivery of Doligos.

Acknowledgements We thank the Misses Ayako Yoshida and Mikiko Yokochi for technical assistance and Hisamitsu Pharmaceutical Co., Ltd. for the donation of PDP iontophoretic apparatuses, ADIS-4030. This research was supported by a grant-in-aid for Encouragement of Young Scientists from the Ministry of Education, Culture, Sports Science, and Technology of Japan (09772031) to H. Arima and a grant from the Nakatomi Foundation to S. Tsuchiya.

\section{REFERENCES AND NOTES}

1) Present address: Graduate School of Pharmaceutical Sciences, Kumamoto University, 5-1 Oe-honmachi, Kumamoto 862-0973, Japan.

2) Agrawal S., Zhao Q., Curr. Opin. Chem. Biol., 2, 519-528 (1998).

3) Crook S., Biotechnol. Genet. Eng. Rev., 15, 121-157 (1998).

4) Fiorentino D. F., Bond M. W., Mosmann T. R., J. Exp. Med., 170, 2081-2095 (1989).

5) Moamann T. R., Coffman R. L., Ann. Rev. Immunol., 7, 145-173 (1989).

6) Leung D. Y. M., Clin. Exp. Immunol., 107, 25-30 (1997).

7) Ohmen J. D., Hanifin J. M., Nickoloff B. J., Rea T. H., Wyzykowski R., Kim J., Jullien D., McHugh T., Nassif A. S., Chan S. C., Modlin R. L., J. Immunol., 154, 1956-1963 (1995).

8) Lester M. R., Hofer M. F., Gately M., Trumble A., Leung D. Y. M., J. Immunol., 154, 6174-6181 (1995).

9) Arima H., Takahashi M., Aramaki Y., Sakamoto T., Tsuchiya S., Antisense Nucleic Acid Drug Dev., 8, 319-327 (1998).

10) Kallmann B., Kolb H., Huther M., Martin S., Hellermann M., Lampeter E., Arch. Dermatol., 132, 1133-1134 (1996).

11) Moore K. W., O’Garra A., Waal R. de, Vieira P., Mosmann T. R., Annu. Rev. Immunol., 11, 165-190 (1993).

12) Grewe M., Bruijnzeel-Koomen C., Schopf E., Thepen T., LangeveldWildschut A., Ruzicka T., Krutmann J., Immunol. Today, 19, 359361 (1998).

13) Nolen H., Cats P., Friend D., Int. J. Pharmaceut., 107, 169-177 (1994).

14) Vlassov V., Nechaeva M., Karamyshev V., Yakubov L., Antisense Res. Dev., 4, 291-293 (1994).

15) Oldenburg K. R., Vo K. T., Smith G. A., Selick H., J. Pharm. Sci., 84, 915-921 (1995).

16) Brand R. M., Iversen P., Pharm. Res., 13, 851-854 (1996).

17) Brand R. M., Haase K., Hannah T. L., Iversen P. L., J. Invest. Dermatol., 111, 1166-1171 (1998).

18) Zewert T. E., Pliquett U. F., Langer R., Weaver J. C., Biochem. Biophys. Res. Commun., 212, 286-292 (1995). 
19) Regnier V., Préat V., Pharm. Res., 15, 1596-1602 (1998).

20) Okabe K., Yamaguchi H., Kawai Y., J. Control Release, 4, 79-85 (1986).

21) Scheuplein R. J., Blank I. H., Bruner G. J., MacFarlane D. J., J. Invest.
Dermatol., 52, 63-70 (1969).

22) Banga A., Chien Y., J. Control Release, 8, 1-24 (1998).

23) Brand R. M., Wahl A., Iversen P. L., J. Pharm. Sci., 87, 49-52 (1998). 